\title{
DO SURGIMENTO DA PROPRIEDADE RURAL AOS PRIMEIROS PASSOS LEGAIS PARA UMA REFORMA AGRÁRIA NO BRASIL
}

\author{
Pedro Fernando Cataneo ${ }^{1}$
}

RESUMO: O presente artigo tem por objetivo fazer um levantamento histórico da propriedade rural, começando em seu nascimento, passando por sua evolução, até chegar ao surgimento dos primeiros passos para uma reforma agrária no Brasil.

Palavras-chave: propriedade rural, reforma agrária, Estatuto da Terra.

\section{INTRODUÇÃO}

Nas primeiras sociedades do mundo, pela própria condição de vida do homem primitivo, o solo era um bem que pertencia a todos os membros das tribos ou famílias, sendo desfrutado por todos. As propriedades pessoais restringiam-se a bens móveis, particularmente os de uso pessoal.

O presente estudo tem por escopo estudar a evolução histórica da propriedade rural no Brasil, do seu nascimento até os primeiros anseios de uma reforma agrária.

\section{DESENVOLVIMENTO}

${ }^{1}$ Professor Doutor, UNESP/Tupã. E-mail: pedro@tupa.unesp.br. 


\section{Formação da propriedade rural no Brasil}

De acordo com Souza Filho e Trybus ${ }^{2}$, a propriedade individual, absoluta e exclusiva, é uma construção humana. Seu marco fundamental é o surgimento dos Estados nacionais.

\section{Explicam Terré e Simler:}

Quand les hommes ne vivent que de la chasse, de la pêche et de la cuillette des fruits sauvages, il n'est pas question d'une appropriation de la terre telle que nous la connaissons. ${ }^{3}$

De acordo com Diez-Picazo:

Al mismo tiempo, la economia liberal,fundada enel esquema del 'laissez faire', configura la propiedad como una mera y abstracta titularidad, con una notable indiferencia hacia sus contenidos reales. ${ }^{4}$

A regulação jurídica da propriedade faz-se através de um esquema abstrato, igual qualquer que seja seu objeto, seja um latifúndio ou um par de sapatos e, por ser fundado no liberalismo econômico e na livre iniciativa, consagra a liberdade dos titulares dos direitos quanto à destinação dos bens e suas possibilidades de utilização e de gozo.

A propagação dessas idéias, mesmo com as restrições que o direito de propriedade atualmente enfrenta, permite que os proprietários que não destinam seus imóveis rurais total ou parcialmente à sua função social, ainda gozem de injustificável proteção.

Antes mesmo do descobrimento do Brasil por Portugal, o regime da propriedade agrária brasileira já havia começado, pois, em decorrência de diversos tratados, como o

\footnotetext{
${ }^{2}$ Carlos Frederico Marés de Souza Filho, Daiana Trybus. O problema na efetivação da função social da propriedade rural imóvel. Disponível em <http://www2.pucpr.br/educacao/pibic/evento/vimp/MPCH07.html>.

${ }^{3}$ François Terré, Philippe Simler. Droit civil: les biens, p. 64.

${ }^{4}$ Luis Diez-Picazo. Fundamentos del derecho civil patrimonial: las relaciones juridico-reales, el registro de la propiedad, la posesion, p.64.
} 
de Alcáçovas (1479), a Bula Inter Coetera (1492) e o de Tordesilhas (1494) confirmado pela bula papal, Ea Quae, em 1504, as terras existentes já pertenciam a Portugal.

$\mathrm{Na}$ colonização do Brasil, Portugal aplicou um método que não representava encargos e que já tinha sido utilizado com sucesso, tanto na metrópole, como em algumas ilhas atlânticas: o regime de sesmarias.

De acordo com Nascimento (1989), esse regime além de não ser novo, não era sequer específico para nossas condições e "tem sua origem em medidas constantes das Ordenações Afonsinas, que foram editadas em 1446, e numa Lei de 26 de junho de 1375, de D. Fernando, Rei de Portugal e Algarves". ${ }^{5}$

Afirma Zanatta que o regime de sesmarias é

[...] antigo costume verificado em algumas regiões da península ibérica, que consistia na divisão de terras particulares inaproveitadas, ainda que contra a vontade do respectivo proprietário, para fins de distribuição entre aqueles que as quisessem explorar durante determinado período, mediante o pagamento de uma renda equivalente à sexta parte dos frutos produzidos. ${ }^{6}$

Portugal nessa época encontrava-se na disputa pela hegemonia econômica da Europa e deixou as terras brasileiras relegadas ao semi-abandono.

Com exceção da doação, em 1504, da llha Fernando de Noronha (na época llha de São João), na prática a colonização só iniciou a partir de 1530, quando D. João III, nomeou como Governador-Geral Martim Afonso de Souza, dando a ele amplos poderes para conceder terras às pessoas que aqui viessem e quisessem viver e povoar.

Diz Miguel Neto ${ }^{7}$ que, posteriormente, insatisfeito com os Governos-Gerais, D. João III, promoveu a divisão da colônia em capitanias hereditárias ou donatárias hereditárias, que se constituíam em terras doadas, pelo rei de Portugal, governador e administrador perpétuo da Ordem e Cavalaria do Mestrado de Cristo, cujo objetivo principal era, evidentemente, a colonização das terras recentemente descobertas.

\footnotetext{
${ }^{5}$ Tupinambá Miguel Castro do Nascimento. A ordem econômica e financeira e a nova constituição: artigo 170 a 192. p.74.

${ }^{6}$ Odair Zanatta. A titulação da terra rural no Brasil. p.168.

${ }^{7}$ Sulaiman Miguel Neto. Questão agrária. p. 26.
} 
Esse regime vigorou no Brasil entre 1532 e 1548, caracterizando-se pela não existência de transladação legal do domínio da terra, visto que as concessões visavam à cultura da terra.

A carta de doação da Capitania Hereditária era acompanhada pelo foral ou carta de foral, meio através do qual o Rei de Portugal fazia a concessão de sesmarias. O foral continha registros dos direitos e obrigações do donatário, possibilitando a resolução à concessão da terra em caso de seu não-aproveitamento.

Todo esse sistema de colonização mostrou-se inviável, iniciando-se, a partir de 1549 um sistema centralizado do poder na pessoa do representante do Rei, o GovernoGeral do Brasil, assentado em um "Regimento" que disciplinava o exercício de poderes por parte dos donatários, a exploração de riquezas e a cobrança de tributos.

O "Regimento" era composto de quarenta e cinco capítulos, dos quais seis tratavam da doação e regulamentação de sesmarias. O regime de concessão de terras, todavia, não sofreu nenhuma alteração substancial.

O "Regimento" buscava evitar a concessão de grandes dimensões de terras que viessem a ser não aproveitadas, sem uso, sem cultivo e sem trabalho. Na prática obtevese o oposto: o regime de sesmarias propiciou a criação de grandes latifúndios.

A história da colonização atingiu seu terceiro período com a publicação da Carta Régia, em 27 de dezembro de 1695, estabelecendo o máximo de cinco léguas como área que poderia ser objeto da doação. Apesar das grandes propriedades continuarem com suas enormes plantações de cana-de-açúcar, o teto máximo estipulado foi sofrendo limitações gradativas, cujo objetivo era o melhor aproveitamento econômico da terra.

Segundo Guimarães ${ }^{8}$, foram baixadas leis que restringiam os tetos máximos de doação, no intuito de cercear o sistema sesmarial, que permitia privilégios sobre incomensuráveis áreas. Essas leis responderam aos insistentes abusos e às repetidas demandas nas quais os senhores mais poderosos levavam a melhor, em prejuízo da marcha da colonização que se desejava acelerar.

O quarto período, que se estendeu até 1795 , teve como destaque a publicação da Carta Régia em 20 de janeiro de 1699. Foi uma fase em que se tentou dar cunho oficial

${ }^{8}$ Alberto Passos Guimarães. Quatro séculos de latifúndio, p. 53. 
às doações de terras feitas pelos delegados régios. Eram necessárias a revisão e a confirmação real dos atos de doação.

Tendo como marco o alvará de 05 de outubro de 1795, que acrescia às exigências para a manutenção da terra, a medição e demarcação das áreas concedidas, iniciou-se o último período de colonização. Um alvará anterior, datado de 05 de janeiro de 1785 reiterava que a cultura (atividade agrícola) era a condição sine qua non para a concessão de sesmarias.

No entanto, as medições eram raramente feitas, devido ao alto custo e pela insuficiência de técnicos para realizá-las. Como destaca José Augusto Gomes de Menezes, a situação de fato que emergiu das exigências legais da Coroa e de sua consequente não exequibilidade foi desastrosa:

\begin{abstract}
Das faltas de medições nasceu a maior desordem, porque ciente ou incientemente foram os posseiros entrando, e quando mais descobertas as regiões, foram melhor conhecidas as localidades, grandes estabelecimentos existiam já nas terras concedidas. E por essa mesma ignorância que tinha o posseiro do que compreendia o concedido, novas concessões de sesmarias se verificaram dentro das já concedidas, e quando o tempo mostrou o erro, os estabelecimentos estavam já feitos. Desta marcha das coisas nasceram mais demandas do que se deram sesmarias no Brasil; e se excetuarmos um ou outro sesmeiro que mediu e realizou toda a terra que lhe fora dada, grande parte deixou cair as sesmarias em comisso, e o maior número contentou-se com cultivar uma parte delas. Já tarde o Sr. D. João VI pretendeu melhorar este estado de coisas e por seu Alvará de 25 de janeiro de 1809 ordenou que a Mesa do Desembargo do Paço não mandasse passar carta de concessão de sesmaria ou de confirmação das que concedessem os governadores e capitães-generais, sem sentença passada em julgado. (...) As demandas, pois à proporção que a população ia crescendo e se movendo para o interior, recresceram e chegaram as coisas ao ponto que em 1822 se julgasse melhor não fazer mais concessões de terras por título de sesmaria, porque a experiência havia mostrado que produziam elas mais desordens entre os cultivadores e punham cada vez mais duvidosa a propriedade territorial. ${ }^{9}$
\end{abstract}

Em Decreto de 10 de dezembro de 1796, por suspensão da execução do Alvará de 05 de outubro de 1795, a Coroa Portuguesa reconheceu seu fracasso no sentido de coibir a concentração de terras nas mãos de alguns proprietários.

\footnotetext{
${ }^{9}$ José Augusto Gomes de Menezes. Rápido exame da lei sobre as terras devolutas e colonização. p. 9/11.
} 


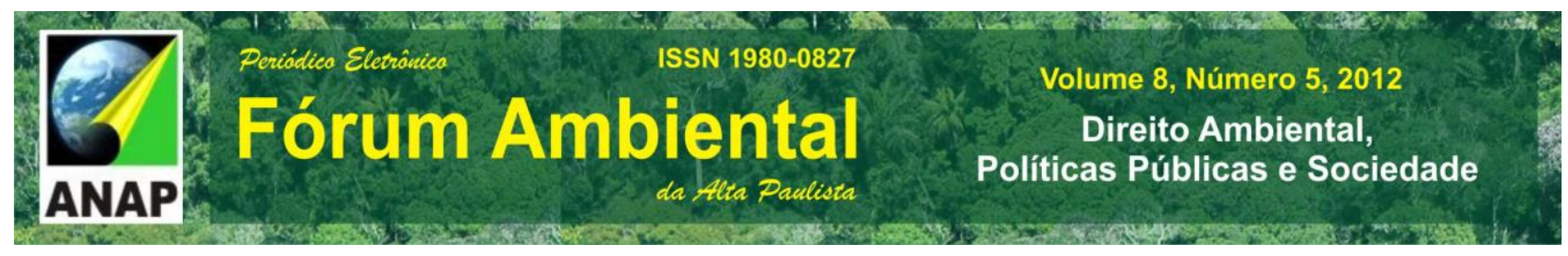

O século XVIII marcou definitivamente a estratificação da propriedade agrícola. O crescimento generalizado das atividades econômicas, tanto urbanas quanto rurais, serviu para monopolizar ainda mais a terra e reforçar o poder dos senhores de engenho.

Ao final do ciclo da mineração, a agricultura encontrava-se em estado alarmante, causado, em grande parte, pela legislação sesmarial. Em decorrência dessa situação, o regime sesmarial foi extinto definitivamente pela Resolução de 17 de julho de 1822, obrigando as autoridades a tomarem outro caminho para a defesa dos privilégios da propriedade latifundiária, colocado em crise pelas "ocupações".

Apesar de revogado, na prática o sistema sesmarial, como lembra João Batista Medeiros de Sousa, continuou a funcionar, embora não se fizessem novas concessões:

[...] na prática a legislação portuguesa a respeito de problemas fundiários, com insignificantes alterações continuou a viger, o que trouxe sérios inconvenientes, mormente pela pouca adequação de suas normas ao Brasil. $\mathrm{Na}$ realidade, proclamada a Independência em 1822, permaneceram em vigor no País as Ordenações do Reino, no caso as Filipinas, demais leis e decretos portugueses, desde que datados de até 25 de abril de 1821, por força de disposição da Lei de 20 de outubro de 1823. A legislação portuguesa só viria a ser revogada com a vigência da Constituição Imperial de 1824 , da qual nasceu o direito positivo brasileiro propriamente dito. ${ }^{10}$

O período de 1822 a 1850 é conhecido como período extralegal ou das posses. Nesse período foi promulgada a primeira Lei de Terras no Brasil. Suspensas as concessões de terras e na inexistência de disciplina legal que regulasse a aquisição de terras no país, tem início a fase da formação da estrutura fundiária brasileira caracterizada pela ocupação. Todas as terras não concedidas por meio de sesmarias, sem quaisquer restrições ficaram à mercê de quem se apropriasse, tornando-se a ocupação a forma de aquisição da propriedade.

O confuso quadro fundiário já existente agravou-se ainda mais. Com o intuito de solucionar ou corrigir distorções foi promulgada a Lei oㅡ 601, de 18 de setembro de 1850, fonte do direito agrário brasileiro, considerada um marco legislativo. Na prática, como explica José de Souza Martins, contribuiu definitivamente para a desigualdade no acesso à terra:

${ }^{10}$ João Bosco Medeiros de Sousa. Direito agrário: lições básicas, p. 19. 
O regime de propriedade que então havia era o regime de sesmarias, suspenso em 1822, poucos meses antes da Independência. Apesar de suspenso, não foi imediatamente substituído por um novo direito de propriedade. Na prática ele continuava funcionando, embora o governo não fizesse novas concessões sesmariais. Se o regime de sesmarias fosse plenamente restabelecido e continuasse em vigor após o fim da escravidão, que obviamente estava próximo com a diminuição do número de escravos, os trabalhadores pobres e livre e os libertos ocupariam livremente as terras disponíveis e não iriam trabalhar para os fazendeiros. Era necessário, portanto, criar um direito de propriedade que fosse, ao mesmo tempo, um obstáculo ao livre acesso à terra por parte da massa da população pobre, inclusive por parte dos ex-escravos, daqueles que viessem a ser libertados da escravidão. (...) A fórmula encontrada foi a de aprovar uma nova lei de terras. Essa lei (Lei no 601, de 1850) tornou-se o oposto da Lei de Colonização, aprovada nos Estados Unidos mais ou menos na mesma época. Lá as terras da fronteira, as terras do Oeste, foram abertas à livre ocupação dos colonos, mediante supervisão e controle do governo. Essa foi a reforma agrária americana, que assegurou a transformação do Oeste num dos grandes celeiros mundiais de alimentos, inicialmente com a agricultura familiar. (...) No Brasil fez-se o contrário. Tratou-se de aprovar um regime de propriedade que impedisse o acesso à propriedade da terra a quem não tivesse dinheiro para comprá-la, mesmo que fosse terra pública ou terra devoluta. Para obter a legitimação do direito à terra havida era necessário que a pessoa pagasse por ela. ${ }^{11}$

Para a transferência de terras públicas para particulares optou-se pela venda em hasta pública, privilegiando sobremaneira a elite que dispunha de capital para fazer frente a essa transação, em detrimento dos economicamente mais fracos.

Esse foi o primeiro golpe mortal à igualdade na distribuição do solo, gerador de efeitos de cunho econômico e social: havia a garantia de mão-de-obra sem possibilidade de acesso à terra, portanto sem opção de trabalho, valorizando ainda mais o patrimônio daqueles que adquiriram o solo. A capacidade financeira para aquisição tornou-se o único limite à apropriação da terra. $\mathrm{O}$ artigo 4 da referida lei também trouxe vantagens apenas à classe proprietária já existente, pois determinava a revalidação das sesmarias ou outras concessões do Governo, geral ou provincial, as quais se achassem cultivadas ou com princípio de cultura.

Não era o verdadeiro intento da Lei de Terras propiciar modificação no regime de distribuição de terras no Brasil. Assim, como se poderia esperar, duas situações distintas ocorreram: de um lado, os latifúndios, ou seja, a concentração de extensas áreas improdutivas em mãos de poucos e, de outro lado, a grande quantidade de minifúndios.

${ }^{11}$ José de Souza Martins. A questão agrária brasileira e o papel do MST , p. 13-14. 
De forma inexorável ocorreu o fortalecimento de uma elite agrária que não guardava qualquer compromisso com a destinação correta que deveria dar às suas terras. Foi concebida a propriedade que se traduzia no domínio exclusivo, ilimitado e perpétuo, mantida em toda a sua plenitude pela primeira Constituição de 1891, no $§ 17$ do artigo 72 .

A doutrina da função social da propriedade que já havia sido transformada em princípio constitucional pela primeira vez, na Constituição Mexicana de 1917, e esteve presente na Constituição alemã de Weimar de 1919, só veio a ocorrer na Constituição brasileira de 1934. Porém não teve valor prático, devido à curta vida desta Constituição, influenciada pelo fechamento do Congresso em novembro de 1937.

A Constituição Federal promulgada em setembro de 1946, retomou os rumos da Constituição de 1934, condicionando o uso da propriedade à sua função social. A estrutura agrária concentracionista, no entanto, resistia à adoção dos princípios constitucionais. Persistiam os interesses dos grandes proprietários, que agregavam a propriedade da terra e o poder político.

Com exceção de algumas inserções políticas, de pouca relevância, e leis esparsas, de amplitude setorial, como, por exemplo, o Estatuto da Lavoura Canavieira, Decreto-lei no 3.855/41, a situação no campo manteve-se inalterada desde 1850 até o início dos anos 60 (1960).

Só se abriu espaço para o segundo marca na evolução legislativa nacional sobre o problema do campo a partir do início dos anos 60. Essa abertura foi fruto de pressões sociais, de movimentos populares no campo e de compromissos internacionais que o Brasil assumiu na Carta de Punta del Este. O fato histórico para esse marco foi a Emenda Constitucional no 10, de 09 de novembro de 1964, que conferiu autonomia legislativa ao Direito Agrário, inserindo-o no rol das matérias de competência legislativa exclusiva da União.

O Estatuto da Terra, Lei no 4.504/64 foi implementado em 30 de novembro de 1964, surgindo como um dos instrumentos legislativos hábeis a iniciar uma política agrária no país e a tratar a reforma agrária de uma forma coerente. Despertou opiniões otimistas, como a de José de Souza Martins: 
opiniões em dois sentidos: é uma lei de bom nível técnico-legislativo e constitui instrumento hábil aos fins a que se propõe, particularmente à reforma agrária. ...Na realidade, o Estatuto da Terra rompeu 'o vetusto liberalismo econômico que se implantou no regime das terras rurais no Brasil....

No plano jurídico o Estatuto da Terra poderia efetivar uma reestruturação efetiva da propriedade agrária no Brasil. Entretanto, na prática, com a implementação de uma política agrícola transformadora e produtiva, não representou avanços significativos. Como demonstra Sônia Helena Novaes Guimarães Moraes:

Aqui neste tópico pode-se retomar a questão da teoria e da prática, da eficiência e da ineficácia do plano legal e o direcionamento político do Estado, tão reticente quanto à aplicação de normas relativas a uma ampla Reforma Agrária no país.

Surgem, portanto, alguns questionamentos do seguinte teor: o "Estatuto da Terra", que incorpora o princípio de função social como um limite ao direito de propriedade - regulamentando o respectivo princípio constitucional - não consegue se impor como tal e, por conseqüência, a Reforma Agrária Brasileira não consegue se realizar; este princípio, assim incorporado à legislação do país tem sido insuficiente como fundamentação da intervenção do Estado no domínio privado; além do mais, a correlação de forças políticas no país tem permitido propostas de tal ordem, ou seja, não tem permitido, nesta sociedade conservadora por excelência, que, mesmo existindo instrumentos legais (tímidos ou não) se tome uma decisão política de aplicá-los. Assim, a questão política e a questão jurídica, só podem ser consideradas conjuntamente.... ${ }^{13}$

O Estatuto da Terra simbolizou, ainda que timidamente e com todas as suas deficiências, uma tentativa de disciplinar o problema. Pode ser considerado progressista sob este aspecto. No entanto, pode representar um processo contraditório dos governos militares quando encarado de outro ângulo. No seu livro "Campo e Cidade no ordenamento jurídico brasileiro", nos relata o Professor Ricardo Pereira Lira:

O fato é que os governos militares, na mesma medida em que promulgavam o Estatuto da Terra e nominalmente criavam as condições jurídicas para a desapropriação das terras com a possibilidade da indenização paga em títulos da dívida pública resgatáveis a longo prazo, desenvolviam simultaneamente uma política de ocupação do Centro-Oeste do País e da Amazônia Brasileira, através de subsídios a grandes empresas, que passaram a comprar imensos tratos de terra, expulsando, com o uso da força, milhares de posseiros, que engrossavam o contingente dos "sem-terra", agravando substancialmente a questão agrária

\footnotetext{
12 José de Souza Martins. A questão agrária brasileira e o papel do MST, p. 23-24.

${ }^{13}$ Sônia Helena Novaes Guimarães Moraes. A questão da propriedade da terra: conceitos e princípios incorporados ao direito agrário latino-americano e a necessidade de uma evolução, p. 72.
} 
nacional, e aumentando significativamente os conflitos decorrentes da luta pela posse da terra. ${ }^{14}$

Como já citado, não se pode deixar sem análise a Constituição de 1988, assim como a forma utilizada pelo segmento conservador dos constituintes para conseguir assegurar determinados privilégios aos proprietários de terras. O Professor Ricardo C. Pereira Lira destaca o fato:

[...] os conservadores conseguiram engessar as tentativas de implantação da reforma agrária, que, antes da Constituição de 1988, dependia apenas da decisão política de efetivamente realizá-la, e que, hoje, está na dependência da promulgação de leis complementares e ordinárias, que lhe permitam a execução. (...) se, de um lado, a estrutura fundiária agrária, no Brasil, continua de fato concentracionista e latifundiária, apesar do retrocesso representado pela Constituição Federal de 1988, a implementação da reforma agrária é uma questão de decisão política, sendo visíveis e conhecidos os caminhos que conduzem a esse resultado, que é um imperativo da Justiça Social. ${ }^{15}$

Os temas relativos à reforma agrária sofreram pouca alteração na Constituição de 1988. O direito de propriedade e outras questões diretamente ligadas à vida fundiária mantiveram-se no mesmo nível da legislação já editada.

\section{CONCLUSÃO}

Na esfera jurídica, o Estatuto da Terra, surgiu como um instrumento capaz de iniciar uma política agrária no país e tratar da reforma agrária de forma eficaz, porém não demonstrou um avanço significativo.

O grande marco foi que o Estatuto da Terra, simbolizou uma tentativa de solucionar o problema, e foi até considerado inovador neste aspecto.

\footnotetext{
${ }^{14}$ Ricardo César Pereira Lira. Campo e cidade no ordenamento jurídico brasileiro. p. 30.

${ }^{15}$ Ricardo César Pereira Lira. Campo e cidade no ordenamento jurídico brasileiro. p. 33-34.
} 
A legislação que diz respeito à reforma agrária, pouco se alterou na Constituição de 1988. Tanto o direito a propriedade como as regras que remetem a vida fundiária permaneceram praticamente idênticas, ou seja, pouca coisa foi mudada.

Talvez essa seja esta umas da principais razões da Reforma Agrária no Brasil caminhar tão lentamente, outro fator que explica a demora com que a reestruturação fundiária no Brasil é feita, sem dúvida, é o elevado tempo de uma política de distribuição injusta de terras.

São problemas que, apesar de comuns a todas as regiões no que diz respeito à distribuição de terras, demandam planos de ação diferenciados de acordo com a região e a situação temporal do país.

\section{REFERENCIAL}

DÍEZ-PICAZO, Luis. Fundamentos del Derecho civil patrimonial, vol. III, (Las relaciones jurídico-reales, el Registro de la Propiedad, la Posesión). 4⿳a . ed. Civitas: Madrid, 1995.

GUIMARÃES, Alberto Passos. Quatro séculos de latifúndio. Rio de Janeiro: Paz e Terra, 1968.

LIRA, Ricardo César Pereira. Campo e Cidade no Ordenamento Jurídico Brasileiro. Rio de Janeiro: Gráfica Pio X Editora, 1991.

MARTINS, José de Souza. A questão agrária brasileira e o papel do MST. In: A reforma agrária e a luta do MST. Petrópolis: Vozes, 1997.

MENEZES, José Augusto Gomes de. Rápido exame da lei sobre as terras devolutas e colonização. Itaborahy: Typ. De J.H. de M. Drumond, 1830.

MIGUEL NETO, Sulaiman. Questão Agrária. 1a ed. Campinas: Bookseller, 1997.

MORAES, Sônia Helena Novaes Guimarães. A questão da propriedade da terra: conceitos e princípios incorporados ao direito agrário latino-americano e a necessidade de uma evolução in Revista de Direito Agrário e Meio Ambiente. Curitiba, Agosto de 1987.

NASCIMENTO, Tupinambá Miguel Castro do. A ordem econômica e financeira e a nova constituição: artigo 170 a 192 . Rio de Janeiro: Aide, 1989. 
SOUSA, João Bosco Medeiros de. Direito Agrário: Lições Básicas. 3ạ. ed. São Paulo: Saraiva, 1994

SOUZA FILHO, Carlos Frederico Marés de; TRYBUS, Daiana. O problema na efetivação da função social da propriedade rural imóvel. Disponível em <http://www2.pucpr.br/educacao/pibic/evento/vimp/MPCH07.html>.

TERRE, François; SIMLER, Philippe. Droit civil: Les biens. 7ª̣. ed., Paris: Dalloz, 2006.

ZANATTA, Odair. A titulação da terra rural no Brasil. INCRA: 1984. 